\title{
Comparison of Shockwave Lithotripsy and Laser Ureterolithotripsy for Ureteral Stones
}

\author{
(1) Tuncer Bahçeci1', (1) Fuat Kızılay², (1) Ahmet Çağ Çal2, (1) Adnan Şimşir² \\ 1Şanlıurfa Training and Research Hospital, Clinic of Urology, Şanlıurfa, Turkiye \\ 2Ege University Medical Faculty Hospital, Clinic of Urology, İmir, Turkiye
}

\section{What's known on the subject? and What does the study add?}

Shockwave lithotripsy (SWL) has lost its popularity, relative to ureteroscopic lithotripsy (URS), due to enhanced endourological instruments. SWL incurred increased costs due to the need for secondary interventions in many countries. SWL is one of the most successful treatment methods when done by experienced person. Altough cost of SWL differs from country to country SWL is very cheap than URS in Turkish health insurance policies.

\begin{abstract}
Objective: This study aimed to compare shockwave lithotripsy (SWL) with ureteroscopic lithotripsy (URS) for ureteral stones in terms of stone-free rates, complication rates, and overall treatment costs.

Materials and Methods: Data of 886 adult patients who underwent URS or SWL were retrospectively evaluated, of which 184 patients underwent SWL and 702 underwent URS. The groups were compared in terms of patient characteristics, stone-free rates, complications, and costs.

Results: No significant differences were found between the groups in terms of age, gender, and relevant sides ( $p>0.05)$. A significant difference was observed in favor of SWL for upper ureteral stones $<10 \mathrm{~mm}$ regarding treatment success $(p=0.018)$, and no significant difference was observed between the two groups in terms of mid-and distal ureteral stones ( $p=1$ and $p=0.655$, respectively). Complications were classified according to the modified Clavien-Dindo grading system. No major complications were observed in the two groups, except for one patient with Clavien-Dindo grade IVa complication. SWL was significantly more economical than URS $(p<0.001)$.

Conclusion: The results of this study suggest that SWL can be recommended as the primary treatment option for upper ureteral stones $<10 \mathrm{~mm}$ because of its high stone-free rates and low overall costs.
\end{abstract}

Keywords: Ureteral stones, ureterorenoscopy, shockwave lithotripsy, holmium laser

\section{Introduction}

Urinary stone disease is still one of the most commonly observed problems of modern society (1). One-fifth of urinary system stones are ureteral stones. Treatment methods of ureteral stones include medical expulsive therapy (MET), ureteroscopic lithotripsy (URS), shockwave lithotripsy (SWL), and open or laparoscopic procedures. The two most commonly performed procedures are SWL and URS (2).

SWL can be successfully performed without the need for anesthesia in most cases (3). Although SWL has low morbidity, secondary interventions are frequently required to achieve a stone-free status. Therefore, in treating ureteral stones, SWL is less preferred than other minimally invasive endourological treatment methods.

URS has become the treatment of choice because of its high efficacy and low complication rates for ureteral stones independent of their location (4). According to the validated guidelines, URS is associated with higher stone-free rates than SWL for ureteral stones of any size or position, except for proximal ureteral stones. 
This study aimed to compare SWL and URS in patients presented with ureteral stones according to their stone-free rates, complication rates, and treatment costs.

\section{Materials and Methods}

We identified 886 patients who were diagnosed with ureteral stones and who underwent either SWL or URS at Ege University Faculty of Medicine in Turkey from January 2012 to January 2016. The patients were selected into groups consecutively, while patients' data were analyzed retrospectively. Of the 886 patients, 184 and 702 were treated with SWL and URS, respectively. This study was derived from the corresponding author's dissertation.

The following data were recorded for each patient: age, gender, size, and location of the stones, periprocedural complications, length of hospital stay, use and duration of Double J-stent (DJ stent), stone-free rates, any secondary interventions, and overall treatment costs covered by the Social Security Institution. Patients were excluded if they were younger than 17 years, had bilateral ureteral stones, had preoperative nephrostomy tubes, were pregnant, had undergone unsuccessful surgery in another clinic, had undergone surgery with a pneumatic probe, or did not return for follow-up after the SWL or URS. Patients with a transplanted kidney or presenting with urosepsis were also excluded because any complications may be caused by the treatment modality or the patients' existing comorbidity.

Preoperatively, direct urinary system radiography (DUSG), ultrasonography, intravenous urography, and unenhanced computed tomography (CT) were used as screening methods.

Ureteral stones were divided into three anatomical groups: upper, middle, and lower. Stones were grouped according to their localizations: stones located above the sacroiliac bone are referred to as upper ureteral stones, stones located on the same plane with the sacroiliac bone as mid-ureteral stones, and stones located below the sacroiliac bone as lower ureteral stones. In this study, each stone's longest measurable diameter was accepted as the stone size.

\section{SWL Technique}

SWL was performed by using the Multimed Classic ${ }^{\mathrm{TM}}$ device. Stones were examined using a C-arm fluoroscopy device. None of the patients who underwent SWL received anesthesia. The process was applied while the patient was in a supine position. In this study, SWL was applied by a single experienced clinician.

In each session, 3.000 shockwaves were produced using 15-20 $\mathrm{kV}$ power. Following the first session, patients were called to return after 10 days for DUSG follow-up. The second session of SWL was not performed if the residual stones were $<4 \mathrm{~mm}$.
These patients were treated with MET and advised to return for follow-up 1 month later. Second and third SWL sessions were performed on patients who had stones $>4 \mathrm{~mm}$ in outpatient visits. The mean number of sessions was 1.37 (1-3), and the period between sessions was 7-10 days. Secondary treatment options were applied to patients who were diagnosed with stones $\geq 5 \mathrm{~mm}$ and did not benefit from SWL.

\section{URS Technique}

The ureteroscopy was performed under spinal or general anesthesia. After positioning to lithotomy with appropriate surgical coverage, a semirigid ureteroscope was engaged to the bladder, and both ureteral orifices were observed. Ureteroscopy was then performed in the suspected ureter under the guidance of a 0.035-inch guidewire. Appropriate manipulations were performed with a $7.5 \mathrm{~F} \mathrm{Karl} \mathrm{Storz}{ }^{\circledR}$ ureteroscope to reach the stones. The stones were then completely fragmented using a SureFlex $^{\text {TM }} 550$ micron Holmium YAG laser lithotripter device. If ureterolithotripsy could not be performed because of the narrow ureteral orifice, edema, hematuria, vision loss, mucosal damage, or push-back of the stone, the process was delayed for the second session by applying a DJ stent or nephrostomy tube. For all patients whose stone removal process was left to the second session, ureteroscopy was recorded as unsuccessful. Patients were invited to return 3 weeks after the surgery, and either a DUSG or an unenhanced CT was performed for residual stones. The presence of stones $\leq 4 \mathrm{~mm}$ in the control X-ray or CT image was accepted as stone-free. Secondary treatment options were applied to patients with residual stones ( $>4 \mathrm{~mm}$ ), whose stones could not be reached because of the narrow ureter, and if push-back of the stone to the kidney occurred.

\section{Statistical Analysis}

Statistical analyses were performed using SPSS Windows version 22.0 statistical package. Descriptive statistics are shown as percentages and medians of variables. Variables were compared for the SWL and URS groups. A chi-square test was used to compare numerical variables. If the variables did not fit a normal distribution, the Mann-Whitney $\mathrm{U}$ test was applied. Results were accepted as significant if the " $p$ " value was $<0.05$.

\section{Results}

In the URS group, the mean age was 46 (17-89) years, and the male/female ratio was $2.44(498 / 204)$. In the SWL group, the mean age was $46(17-86)$ years, and the male/female ratio was 2.22 (127/57). No significant difference was found between the two groups regarding the mean age and male/ female ratio ( $p=0.436$ and $p=0.611$, respectively). Demographic data and distribution of stone dimensions for both groups are summarized in Table 1. 
For ureteral stones $<10 \mathrm{~mm}$ in the URS group, the stone-free rates were $82.8 \%(n=77)$ in the proximal ureter, $87.5 \%(n=63)$ in the mid-ureter, and $94.8 \%(n=73)$ in the distal ureter. In the SWL group, for stones $<10 \mathrm{~mm}$, the stone-free rates were $97.6 \%$ in the proximal ureter, $86.7 \%$ in the mid-ureter, and $97.6 \%$ in the distal ureter. Compared with URS, SWL was more effective in proximal ureteral stones $<10 \mathrm{~mm}(p=0.018)$. No significant difference was observed for stones $<10 \mathrm{~mm}$ in the mid- and distal ureters ( $p=1$ and $p=0.655$, respectively). For ureteral stones $>10 \mathrm{~mm}$, the success rates of URS were $84.4 \%$ for proximal ureteral stones, $87.1 \%$ for mid-ureteral stones, and $93.4 \%$ for distal ureteral stones. For ureteral stones $>10 \mathrm{~mm}$, the SWL success rates were $76.9 \%$ in the proximal ureter, $100 \%$ in the mid-ureter, and 93.4\% in the distal ureter. No significant differences were found between URS and SWL regarding stonefree rates for stones $>10 \mathrm{~mm}(p=0.284, p=0.601$, and $p=1$ for the proximal, mid-, and distal ureters, respectively). Compared with stone localization and dimension, treatment success rates are summarized in Table 2 .

Table 1. Demographic data of the patients and stone characteristics

\begin{tabular}{|l|l|l|l|}
\hline & SWL & URS & $p$ \\
\hline Age & $46(17-86)$ & $46(17-89)$ & $p=0.436^{*}$ \\
\hline $\begin{array}{l}\text { Gender } \\
\text { Male, n (\%) } \\
\text { Female, n (\%) }\end{array}$ & $\begin{array}{l}127(20.3) \\
57(21.8)\end{array}$ & $\begin{array}{l}498(79.7) \\
204(78.2)\end{array}$ & $p=0.611^{* *}$ \\
\hline $\begin{array}{l}\text { Stone laterality } \\
\text { Right side, n (\%) } \\
\text { Left side, n (\%) }\end{array}$ & $92(50)$ & $361(51.4)$ & $p=0.731^{* *}$ \\
\hline $\begin{array}{l}\text { Stone location } \\
\text { - Proximal, n (\%) } \\
\text { - Mid, n (\%) } \\
\text { - Distal, n (\%) }\end{array}$ & $92(50)$ & $341(48.6)$ & \\
\hline Stone size (mm) & $94(24.4)$ & $292(75.6)$ & \\
\hline $\begin{array}{l}\text { Mann-Whitney U test, "Chi-square test, SWL: Shockwave lithotripsy, URS: } \\
\text { Ureteroscopic lithotripsy }\end{array}$ & $66(25)$ & $198(75)$ & $p<0.001^{* *}$ \\
\hline
\end{tabular}

Table 2. Stone-free rates according to the stone size and location

\begin{tabular}{|l|l|l|l|l|}
\hline Stone size & Stone location & SWL (n) & URS (n) & $\mathbf{p}$ \\
\hline \multirow{3}{*}{$>10 \mathrm{~mm}$} & Proximal & $40(76.9 \%)$ & $168(84.4 \%)$ & 0.284 \\
\cline { 2 - 5 } & Mid & $9(100 \%)$ & $122(87.1 \%)$ & 0.601 \\
\cline { 2 - 5 } & Distal & $23(95.8 \%)$ & $113(93.4 \%)$ & 1.00 \\
\hline \multirow{3}{*}{$<10 \mathrm{~mm}$} & Proximal & $40(97.6 \%)$ & $77(82.8 \%)$ & 0.018 \\
\cline { 2 - 5 } & Mid & $13(87.6 \%)$ & $63(87.5 \%)$ & 1.00 \\
\cline { 2 - 5 } & Distal & $41(97.6 \%)$ & $73(94.8 \%)$ & 0.655 \\
\hline
\end{tabular}

Chi-square test, SWL: Shockwave lithotripsy, URS: Ureteroscopic lithotripsy

(Table 2 shows the stone-free rates and the number of patients who were stone-free:

166 and 782 patients in the SWL and URS groups were stone-free, respectively. The

remaining 104 patients required secondary treatment)
Complications were classified according to the modified Clavien-Dindo grading system. Intraoperative complications were observed in two patients as Clavien-Dindo grade IIIb (ureteral perforation) and Clavien-Dindo grade IVa (ureteral avulsion) for URS. In four patients, postoperative fever (ClavienDindo grade II) was observed. After the process, a DJ stent was used in 673 patients, whereas it was not used in 29 patients. The usage rate of DJ stent was $95.8 \%$. The average removal time of the DJ stent was 27.52 days. The average hospital stay was 1.15 days; in the URS group, $52(7.4 \%)$ patients were discharged on the same day of their procedure. The rate of steinstrasse formation, as a possible complication of SWL, was $2.17 \%$ and recorded as Clavien-Dindo grade IIIb. All these patients had undergone SWL for stone size $>10 \mathrm{~mm}$. Sepsis was not observed in any patients after SWL. Data regarding minor complications, such as hematuria and flank pain, were not available in the study. In the SWL group, a J-stent was not used in any of the patients, and all patients were discharged on the same day of the treatment. A comparison of stent usage rates, complication rates, and hospitalization time between the URS and SWL groups is summarized in Table 3.

Overall treatment costs for URS and SWL were also analyzed. While the average cost of URS was $131.25 \pm 35.46$ euros $(€)$, the average cost of SWL was $28.1 \pm 11.2 €$. The difference in costs between the two groups was significant $(p<0.001)$. A comparison of the two groups according to the overall treatment costs is summarized in Table 4.

Table 3. Comparison of complications, stent use, and duration of hospital stay

\begin{tabular}{|l|l|l|}
\hline & SWL & URS \\
\hline DJ stent usage & NA & $673(95.8 \%)$ \\
\hline Removal time of the DJ stent & NA & $27.52 /$ day \\
\hline Patients discharged on the same day & $184(100 \%)$ & $52(7.4 \%)$ \\
\hline Complications & $4(2.17 \%)$ & NA \\
\hline Streinstrasse & NA & $4(0.5 \%)$ \\
\hline Postoperative fever & NA & $1(0.14 \%)$ \\
\hline Ureteral avulsion & NA & $1(0.14 \%)$ \\
\hline Ureteral perforation & \multicolumn{2}{|l}{} \\
\hline SWL: Shockwave lithotripsy, URS: Ureteroscopic lithotripsy, DJ stent: Double J-stent \\
\hline
\end{tabular}

Table 4. Overall costs of shockwave lithotripsy vs ureteroscopic lithotripsy

\begin{tabular}{|l|l|l|l|}
\hline & SWL (Euro) & URS (Euro) & $\mathbf{p}$ \\
\hline Mean & 35.4 & 142.8 & \multirow{2}{*}{${ }^{*} \mathrm{p}<0.001$} \\
\cline { 1 - 3 } Median & 28.1 & 131.2 & \multirow{2}{*}{} \\
\cline { 1 - 2 } SD & 11.23 & 35.4 & \\
\cline { 1 - 2 } & & &
\end{tabular}

*Mann-Whitney U test, SD: Standard deviation, SWL: Shockwave lithotripsy, URS: Ureteroscopic lithotripsy 


\section{Discussion}

Various treatment methods are available for ureteral stones. In the selection of treatment, patient preference, physician experience, and equipment availability play an important role. Even if SWL and URS are the two most commonly performed procedures, SWL has lost its popularity, relative to URS, because of the high rates of secondary treatment it requires. URS provides better stone-free rates with increasing reliability, thanks to new, enhanced endourology instruments and parallel advances in endoscopic imaging technology (5). A 2014 study of 194,781 kidney stone treatments reported a fall in the ratio of SWL preference from 69\% to 34\% -along with an increase in URS preference from 25\% to 59\%- from 1991 to 2010 (6).

The current European Association of Urology guidelines have recommended a treatment algorithm for ureteral stones. While SWL was recommended as the first treatment option for upper ureteral stones $<10 \mathrm{~mm}$, URS was recommended for distal ureteral stones $>10 \mathrm{~mm}$. Therefore, for upper ureteral stones $>10 \mathrm{~mm}$ and distal ureteral stones $<10 \mathrm{~mm}$, neither treatment modality was superior to the other (7).

In a prospective randomized study published in 2012, the stonefree rates for SWL and URS of stones $>10 \mathrm{~mm}$ in the upper ureter were $35.7 \%$ and $62.5 \%$, respectively (8). In a 2004 study of 82 patients, the stone-free rates for upper ureter stones $>10 \mathrm{~mm}$ were $92 \%$ and $61 \%$ for URS and SWL, respectively (9). A metaanalysis reported a stone-free rate of $82.6 \%$ for URS in 746 patients with stone $>10 \mathrm{~mm}$ in the upper ureter. Meanwhile, the stone-free rate was $85.5 \%$ in 1.460 patients with stone $<10 \mathrm{~mm}$ in the upper ureter (10). Another meta-analysis revealed that stones $>10 \mathrm{~mm}$ are located at the upper ureter and that URS had higher stone-free rates than did SWL (4). In our study, the stone-free rates of SWL and URS for upper ureteral stones $>10$ $\mathrm{mm}$ were $76.9 \%$ and $84.4 \%$, respectively. For stones $<10 \mathrm{~mm}$, the rates were $97 \%$ and $82.8 \%$, respectively.

In a study conducted on 156 patients with mid- and lower ureteral stones, the SWL and URS stone-free rates were 51\% and $91 \%$, respectively (11). In a retrospective study, the stonefree rates following SWL and URS were 81\% and 99\% for lower ureteral stones and 90\% and 96\% for mid-ureteral stones, respectively (12).

In a meta-analysis of URS, stone-free rates for stones $>10$ $\mathrm{mm}$ were $85.2 \%$ for mid-ureteral stones and $90.9 \%$ for lower ureteral stones. In the same study, the stone-free rates for stones $<10 \mathrm{~mm}$ were $90.8 \%$ for mid-ureteral stones and $95.2 \%$ for lower ureteral stones (10).

In our study, the success rates for mid-ureteral stones $>10 \mathrm{~mm}$ using SWL and URS were $100 \%$ and $87.1 \%$, respectively. For stones $<10 \mathrm{~mm}$, the rates were $86.7 \%$ and $87.5 \%$, respectively.
For lower ureteral stones $>10 \mathrm{~mm}$, the SWL and URS success rates were $95.8 \%$ and $93.4 \%$, and for stones $<10 \mathrm{~mm}$, they were $97.6 \%$ and $94.8 \%$, respectively. The success rate of SWL for midureteral stones $>10 \mathrm{~mm}$ was $100 \%$ because of the low number of patients $(n=9)$.

In the literature, the total post-URS complication rate has ranged from $9 \%$ to $25 \%(4,10,13)$. Early complications include renal colic, hematuria, urinary infection, mucosal injuries, urinary extravasation, ureteral perforation, and avulsion. In our review of the literature, the more enhanced are the instruments used in URS and the more experienced are the surgeons participating in the intervention, the fewer complication rates are reported.

A study determined that the rates of mucosal injury, ureteral perforation, ureteral avulsion, renal colic, and urosepsis were $1.5 \%, 1.7 \%, 0.1 \%, 2.2 \%$, and $1.1 \%$, respectively (13).

In our study, among patients who had undergone URS, four patients had a postoperative fever $(0.5 \%)$, one patient had ureteral perforation $(0.14 \%)$, and one patient had ureteral avulsion $(0.14 \%)$. These values were similar to those reported in the literature.

Complications of SWL are very rarely reported in the literature $(0-6 \%)(14,15)$. The renal colic rate ranged from $2 \%$ to $4 \%(16)$, and the sepsis rate ranged from $1 \%$ to $2.7 \%(17,18)$. The risk of steinstrasse after SWL has ranged from $4 \%$ to $7 \%$ (19-21), and the major risk factor is defined as the stone dimension (22). Wu et al. (9) reported hematuria and flank pain as the most frequent complications; no major complications were determined in the study.

In the present study, steinstrasse formation was seen in $2.17 \%$ of patients undergoing SWL. In all these patients, stone sizes were $>10 \mathrm{~mm}$. After SWL, sepsis was not observed. The complication rates were similar to those reported in the literature. One of the most important factors that affect treatment choice is the overall cost. Owing to the restrictions enforced by health insurance companies in recent years, physicians tended to shorten hospitalization time for all procedures. Several studies have attempted to determine the most cost-effective treatment method in patients diagnosed with ureteral stones.

A study conducted in Taiwan compared URS and SWL for distal ureteral stones. The overall cost analysis results were 1.030 dollars for SWL and 956 dollars for URS (23). Both Francesca et al. (24) and Kapoor et al. (25) have stated that URS was less expensive than SWL as a treatment modality. In all three studies, SWL incurred increased costs as it required secondary interventions. However, in another study, the costs of SWL and URS were comparable (26), and Bierkens et al. (12) found that the treatment costs of SWL for distal and mid-ureteral stones were lower than those of URS. 
In our study, the average treatment cost was significantly lower in the SWL group, which included the cost of secondary treatments. This finding contradicts those of most studies in the literature. This controversial difference is due to a higher stonefree rate after the initial procedure in our study, as well as to the lower cost of SWL in Turkish health insurance policies.

\section{Study Limitations}

This study has some limitations. First, this retrospective study was performed in a single center. Second, there is a discrepancy between the numbers of patients in the two groups. The smaller size of the SWL group was due to the preference of the patients (due to higher rates of secondary interventions required in SWL than in URS) and surgeons (due to being more experienced on URS).

\section{Conclusion}

The results of this study suggest that SWL can be recommended as the primary treatment choice for upper ureteral stones $<10$ $\mathrm{mm}$ because of its high stone-free rate and low overall costs.

*This study was derived from the corresponding author's dissertation.

\section{Ethics}

Ethics Committee Approval: This study complied with the Helsinki Declaration and was conducted with the approval of the local ethics committee (approval number: HRU/21.15.18, date: 06.09.2021).

Informed Consent: Patients' data were analyzed retrospectively.

Peer-review: Externally peer-reviewed.

\section{Authorship Contributions}

Surgical and Medical Practices: T.B., F.K., A.Ç.Ç., A.Ş., ConceptDesign: T.B., F.K., A.Ç.Ç., A.Ş., Data Collection or Processing: T.B., F.K., A.Ş., Analysis or Interpretation: T.B., F.K., A.Ç.Ç., A.Ş., Literature Search: T.B., F.K., Writing: T.B., F.K.

Conflict of Interest: No conflict of interest was declared by the authors.

Financial Disclosure: The authors declare that they have no relevant financial.

\section{References}

1. Pearle $\mathrm{M}$, Lotan Y. Urinary Lithiasis: Etiology, Epidemiology, and Pathogenesis Campbell- walsh urology 9th ed. Section XI Chapter 42:2007.

2. Pearle MS, Calhoun EA, Curhan GC; Urologic Diseases of America Project. Urologic diseases in America project: urolithiasis. J Urol 2005;173:848-857.

3. Doublet JD, Tchala K, Tligui M, Ciofu C, Gattegno B, Thibault P. In situ extracorporeal shock wave lithotripsy for acute renal colic due to obstructing ureteral stones. Scand J Urol Nephrol 1997;31:137-139.
4. Preminger GM, Tiselius HG, Assimos DG, Alken P, Buck AC, Gallucci M, Knoll T, Lingeman JE, Nakada SY, Pearle MS, Sarica K, Türk C, Wolf JS Jr; American Urological Association Education and Research, Inc; European Association of Urology. 2007 Guideline for the management of ureteral calculi. Eur Urol 2007:52:1610-1631.

5. Leone NT, Garcia-Roig M, Bagley DH. Changing trends in the use of ureteroscopic instruments from 1996 to 2008. J Endourol 2010;24:361-365

6. Ordon M, Urbach D, Mamdani M, Saskin R, D'A Honey RJ, Pace KT. The surgical management of kidney stone disease: a population based time series analysis. J Urol 2014;192:1450-1456.

7. Türk $C$, Petřik $A$, Sarica $K$, Seitz $C$, Skolarikos $A$, Straub M, Knoll T. EAU Guidelines on Interventional Treatment for Urolithiasis. Eur Urol 2016;69:475-482.

8. Lopes Neto AC, Korkes F, Silva JL 2nd, Amarante RD, Mattos MH, TobiasMachado M, Pompeo AC. Prospective randomized study of treatment of large proximal ureteral stones: extracorporeal shock wave lithotripsy versus ureterolithotripsy versus laparoscopy. J Urol 2012;187:164-168.

9. Wu CF, Shee JJ, Lin WY, Lin CL, Chen CS. Comparison between extracorporeal shock wave lithotripsy and semirigid ureterorenoscope with holmium:YAG laser lithotripsy for treating large proximal ureteral stones. J Urol 2004;172:1899-1902.

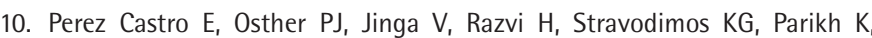
Kural AR, de la Rosette JJ; CROES Ureteroscopy Global Study Group. Differences in ureteroscopic stone treatment and outcomes for distal, mid-, proximal, or multiple ureteral locations: the Clinical Research Office of the Endourological Society ureteroscopy global study. Eur Urol 2014;66:102109.

11. Hendrikx AJ, Strijbos WE, de Knijff DW, Kums JJ, Doesburg WH, Lemmens WA. Treatment for extended-mid and distal ureteral stones: SWL or ureteroscopy? Results of a multicenter study. J Endourol 1999;13:727-733.

12. Bierkens AF, Hendrikx AJ, De La Rosette JJ, Stultiens GN, Beerlage HP, Arends AJ, Debruyne FM. Treatment of mid- and lower ureteric calculi: extracorporeal shock-wave lithotripsy vs laser ureteroscopy. A comparison of costs, morbidity and effectiveness. Br J Urol 1998;81:31-35.

13. Geavlete $P$, Georgescu D, Niță G, Mirciulescu V, Cauni V. Complications of 2735 retrograde semirigid ureteroscopy procedures: a single-center experience. J Endourol 2006;20:179-185.

14. Padhye AS, Yadav PB, Mahajan PM, Bhave AA, Kshirsagar YB, Sovani YB, Bapat SS. Shock wave lithotripsy as a primary modality for treating upper ureteric stones: A 10-year experience. Indian J Urol 2008;24:486-489.

15. Simunovic D, Sudarevic B, Galic J. Extracorporeal shockwave lithotripsy in elderly: impact of age and comorbidity on stone-free rate and complications. J Endourol 2010;24:1831-1837.

16. Tan YM, Yip SK, Chong TW, Wong MY, Cheng C, Foo KT. Clinical experience and results of ESWL treatment for 3,093 urinary calculi with the Storz Modulith SL 20 lithotripter at the Singapore general hospital. Scand J Urol Nephrol 2002;36:363-367.

17. Skolarikos A, Alivizatos G, de la Rosette J. Extracorporeal shock wave lithotripsy 25 years later: complications and their prevention. Eur Urol 2006:50:981-990.

18. Müller-Mattheis $V G$, Schmale $D$, Seewald $M$, Rosin $H$, Ackermann R. Bacteremia during extracorporeal shock wave lithotripsy of renal calculi. J Urol 1991;146:733-736.

19. Madbouly K, Sheir KZ, Elsobky E, Eraky I, Kenawy M. Risk factors for the formation of a steinstrasse after extracorporeal shock wave lithotripsy: a statistical model. J Urol 2002;167:1239-1242.

20. Sayed MA, el-Taher AM, Aboul-Ella HA, Shaker SE. Steinstrasse after extracorporeal shockwave lithotripsy: aetiology, prevention and management. BJU Int 2001;88:675-678. 
21. Ather MH, Shrestha B, Mehmood A. Does ureteral stenting prior to shock wave lithotripsy influence the need for intervention in steinstrasse and related complications? Urol Int 2009;83:222-225.

22. Lucio J, Korkes F, Lopes-Neto AC, Silva EG, Mattos MH, Pompeo AC. Steinstrasse predictive factors and outcomes after extracorporeal shockwave lithotripsy. Int Braz J Urol 2011;37:477-482.

23. Chang $\mathrm{CP}$, Huang $\mathrm{SH}$, Tai HL, Wang $\mathrm{BF}$, Yen MY, Huang $\mathrm{KH}$, Jiang $\mathrm{HJ}$, Lin J. Optimal treatment for distal ureteral calculi: extracorporeal shockwave lithotripsy versus ureteroscopy. J Endourol 2001;15:563-566.
24. Francesca F, Grasso M, Lucchelli M, Broglia L, Cammelli L, Zoppei G, Rigatti P. Cost-efficacy comparison of extracorporeal shock wave lithotripsy and endoscopic laser lithotripsy in distal ureteral stones. J Endourol 1993;7:289291.

25. Kapoor DA, Leech JE, Yap WT, Rose JF, Kabler R, Mowad JJ. Cost and efficacy of extracorporeal shock wave lithotripsy versus ureteroscopy in the treatment of lower ureteral calculi. J Urol 1992;148:1095-1096.

26. Anderson KR, Keetch DW, Albala DM, Chandhoke PS, McClennan BL, Clayman RV. Optimal therapy for the distal ureteral stone: extracorporeal shock wave lithotripsy versus ureteroscopy. J Urol 1994;152:62-65. 